\title{
Management of the recalcitrant upper lip
}

\author{
Al Haitham Al Shetawi ${ }^{1,2}$, Rui Fernandes ${ }^{1}$ \\ 'Division of Head \& Neck Surgery, Department of Oral \& Maxillofacial Surgery, University of Florida Health, Jacksonville, FL 32209, USA. \\ ${ }^{2}$ Maxillofacial, Head \& Neck Surgery, Division of Surgical Oncology, Vassar Brothers Medical Center, Dyson Center for Cancer Care, \\ Poughkeepsie, NY 12601, USA.
}

Correspondence to: Dr. Rui Fernandes, Division of Head \& Neck Surgery, Department of Oral \& Maxillofacial Surgery, University of Florida Health, Jacksonville, FL 32209, USA. E-mail: Rui.fernandes@jax.ufl.edu

How to cite this article: Al Shetawi AH, Fernandes R. Management of the recalcitrant upper lip. Plast Aesthet Res 2018;5:1. http://dx.doi.org/10.20517/2347-9264.2017.61

Received: 4 Sep 2017 First Decision: 18 Jan 2018 Revised: 24 Jan 2018 Accepted: 24 Jan 2018 Published: 29 Jan 2018

Science Editor: You-Bin Wang Copy Editor: Jun-Yao Li Production Editor: Huan-Liang Wu

\begin{abstract}
The aim of this study was to present our experience in the management of the recalcitrant upper lip and describe the surgical technique. We took a retrospective chart review of all patients who underwent reconstruction of the recalcitrant upper lip after maxillectomy and radiation therapy. Three female patients were identified. All patients had a history of malignant maxillary tumors, mucoepidermoid carcinoma $(n=1)$, verrucous carcinoma $(n=1)$, squamous cell carcinoma $(n=1)$. Tumor extirpation was carried out through total maxillectomy $(n=2)$, and bilateral subtotal maxillectomy $(n=1)$. Primary reconstruction was accomplished with scapula free flap $(n=1)$, fibula free flap $(n=1)$, and nonvascularized iliac crest bone graft $(n=1)$. Two patients underwent adjuvant radiotherapy. All patients developed recalcitrant upper lip. All patients had secondary reconstruction to correct of the recalcitrant upper lip using radial forearm free flap. All patients had successful dental rehabilitation. The mean follow-up was 5 years (range 3-7 years). Subjective functional and aesthetic outcome was assessed in all patients at the last follow up visit. All patients reported subjective improvement in speech, mastication and aesthetics. Free tissue transfer provides an ideal method to reconstruct the recalcitrant upper lip. Favorable functional and aesthetic outcomes can be successfully achieved using the technique described in this series.
\end{abstract}

Keywords: Recalcitrant upper lip, upper lip reconstruction, maxillectomy, radiation therapy

\section{INTRODUCTION}

Complex post-ablative reconstruction often requires secondary refinements to improve the aesthetic and functional outcome. A challenging problem encountered after post-ablative maxillary reconstruction and adjuvant radiotherapy is the recalcitrant upper lip. Patients with recalcitrant upper lip present with retracted and shortened upper lip, thin vermilion and intractable vestibule [Figure 1]. This results in lip

\footnotetext{
(@) $\left(\frac{1}{\infty}\right.$

(C) The Author(s) 2018. Open Access This article is licensed under a Creative Commons Attribution 4.0 International License (https://creativecommons.org/licenses/by/4.0/), which permits unrestricted use, sharing, adaptation, distribution and reproduction in any medium or format, for any purpose, even commercially, as long as you give appropriate credit to the original author(s) and the source, provide a link to the Creative Commons license, and indicate if changes were made.
}

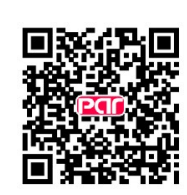



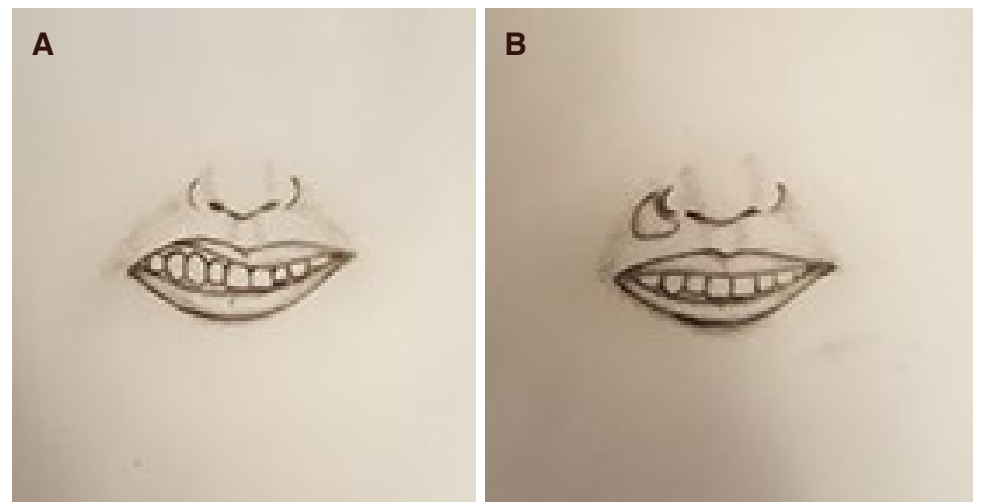

Figure 1. (A) The classic appearance of the recalcitrant upper lip; (B) inset of the radial forearm free flap at the base of the nose and the depth of the oral vestibule improves the lip, vermilion and vestibule

Table 1. Summary of patients

\begin{tabular}{|c|c|c|c|c|c|c|c|c|c|}
\hline Patient & Age & Gender & Diagnosis & $\begin{array}{l}\text { Ablative } \\
\text { treatment }\end{array}$ & $\begin{array}{l}\text { Adjuvant } \\
\text { treatment }\end{array}$ & Primary reconstruction & $\begin{array}{c}\text { Secondary } \\
\text { reconstruction }\end{array}$ & $\begin{array}{l}\text { Follow } \\
\text { up }\end{array}$ & $\begin{array}{c}\text { Dental } \\
\text { rehabilitation }\end{array}$ \\
\hline$\overline{1}$ & 68 years & Female & $\begin{array}{l}\text { Intermediate } \\
\text { grade MEC }\end{array}$ & $\begin{array}{l}\text { Left total } \\
\text { maxillectomy }\end{array}$ & Yes & $\begin{array}{l}\text { Scapulaosteocutaneous } \\
\text { free flap } \\
\text { Orbital floor } \\
\text { reconstruction }\end{array}$ & $\begin{array}{l}\text { Trismus release } \\
\text { Fat grafting } \\
\text { Canthopexy and } \\
\text { tarsorrhaphy } \\
\text { RFFF } \\
\text { Flap debulking }\end{array}$ & 7 years & Yes \\
\hline 2 & 60 years & Female & $\begin{array}{l}\text { Verrucous } \\
\text { carcinoma }\end{array}$ & $\begin{array}{l}\text { Bilateral } \\
\text { subtotal } \\
\text { maxillectomy } \\
\text { Bilateral neck } \\
\text { dissection }\end{array}$ & No & Iliac crest bone graft & $\begin{array}{l}\text { RFFF } \\
\text { Flap debulking }\end{array}$ & 3 years & Yes \\
\hline 3 & 57 years & Female & Stage 4 SCC & $\begin{array}{l}\text { Right total } \\
\text { maxillectomy } \\
\text { Right neck } \\
\text { dissection }\end{array}$ & Yes & $\begin{array}{l}\text { Fibular free flap } \\
\text { Orbital floor } \\
\text { reconstruction }\end{array}$ & $\begin{array}{l}\text { Zygomatic } \\
\text { implants } \\
\text { Fat grafting } \\
\text { Vestibuloplasty } \\
\text { RFFF } \\
\text { Flap debulking }\end{array}$ & 6 years & Yes \\
\hline
\end{tabular}

MEC: mucoepidermoid carcinoma; SCC: squamous cell carcinoma; RFFF: radial forearm free flap

incompetency, difficulty in controlling the food bolus, speech intelligibility and difficulty in prosthetic rehabilitation.

There is paucity of reports in the surgical literature on the management of the recalcitrant upper lip. In this report, we present our experience with three patients [Table 1] using the radial forearm free flap (RFFF) and describe the surgical technique in details.

\section{CASE REPORT}

\section{Case 1}

This is a 68-year-old female with a history of mucoepidermoid carcinoma of the left maxillary sinus. She underwent left total maxillectomy and adjuvant radiotherapy. She subsequently underwent scapula osteocutaneous free flap reconstruction. Multiple secondary procedures were performed to improve her facial symmetry and function including trismus release, fat grafting, canthopexy and tarsorrhaphy. She continued to have the classic appearance of the retracted and shortened upper lip on the affected side with intractable maxillary vestibule [Figure $2 \mathrm{~A}$ ]. RFFF reconstruction was performed to reconstruct the recalcitrant upper lip and oral vestibule [Figure $2 \mathrm{~B}$ ]. The postoperative course was unremarkable. Flap debulking was done to achieve improved symmetry. She was able to wear dental prosthesis and had improved speech and mastication [Figure 2C]. She was followed up for 7 years. 

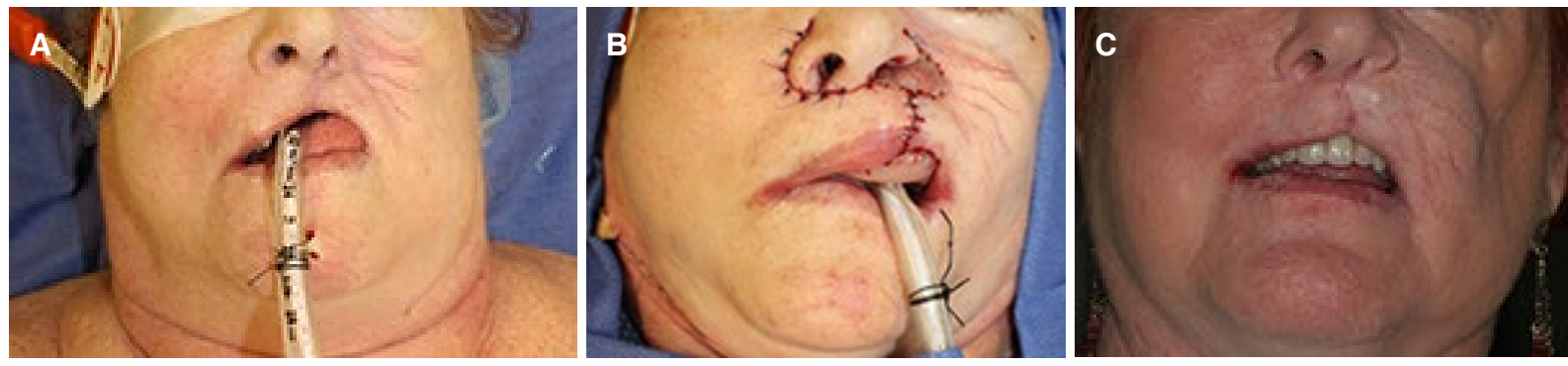

Figure 2. (A) The classic appearance of the shortened and retracted upper lip after primary reconstruction and adjuvant radiation therapy; (B) inset of the radial forearm free flap lengthens the lip and vestibule; and (C) allows placement of dental prosthesis with improved lipto-tooth relationship
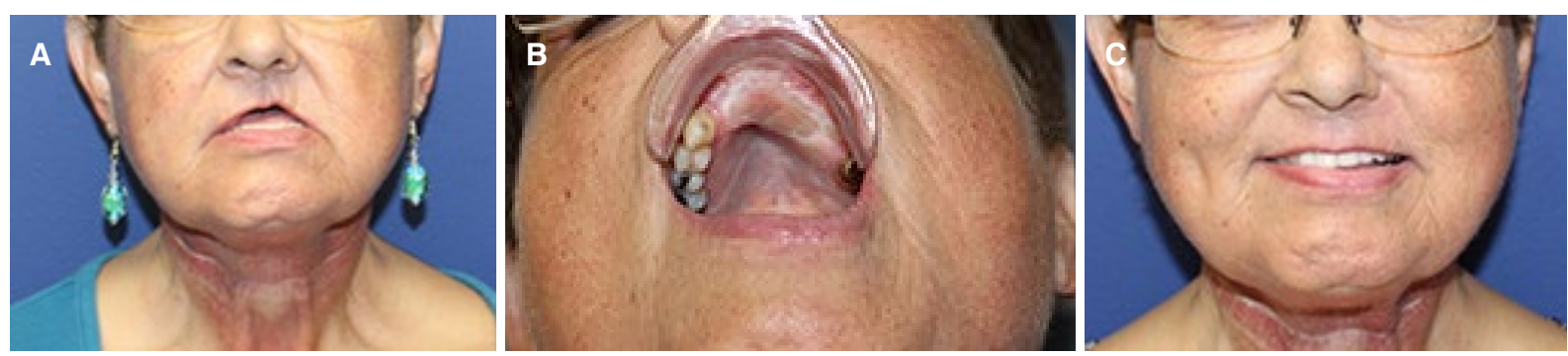

Figure 3. (A) Significant shortening of the upper lip and loss of vestibule after subtotal maxillectomy; (B) inset of the radial forearm free flap at the depth of the neo-vestibule; (C) final appearance with improved lip-to-tooth relationship

\section{Case 2}

This is a 60-year-old female with a history of verrucous carcinoma of the anterior maxilla. She underwent subtotal maxillectomy and bilateral neck dissection. She developed a shortened and retracted upper lip with intractable vestibule [Figure 3A]. She was unable to wear a dental prosthesis. Subsequently she underwent iliac crest bone graft and radial forearm free flap to reconstruct the recalcitrant upper lip and oral vestibule [Figure 3B]. The postoperative course was unremarkable. Flap debulking was performed at a later stage. She was able to wear dental prosthesis and had improved speech and mastication [Figure 3C]. She was followed up for 3 years.

\section{Case 3}

This is a 57-year-old female with a history of squamous cell carcinoma of the right maxilla. She underwent subtotal maxillectomy, neck dissection, fibula free flap reconstruction and adjuvant radiotherapy. She had zygomatic implants. However, due to the loss of vestibule, dental rehabilitation was difficult. She underwent multiple secondary procedures including fat grafting and vestibuloplasty. She continued to have the classic appearance of the retracted and shortened upper lip on the affected side with intractable maxillary vestibule [Figure $4 \mathrm{~A}$ ]. RFFF reconstruction was done to reconstruct the recalcitrant upper lip and oral vestibule. The postoperative course was unremarkable. She subsequently had flap debulking to achieve improved symmetry. She was able to wear dental prosthesis and had improved speech and mastication [Figure 4B]. She was followed up for 6 years.

\section{DISCUSSION}

Ablative surgery disrupts the elegant anatomy of maxilla and the overlying soft tissue. Reconstructive techniques in the primary setting are geared toward achieving bony and mucosal continuity [Figure 5]. Adjuvant radiotherapy leads to soft tissue atrophy and fibrosis. This results in upper lip retraction and shorting, thinning of the vermilion and loss of the intraoral vestibule [Figure 1A]. 

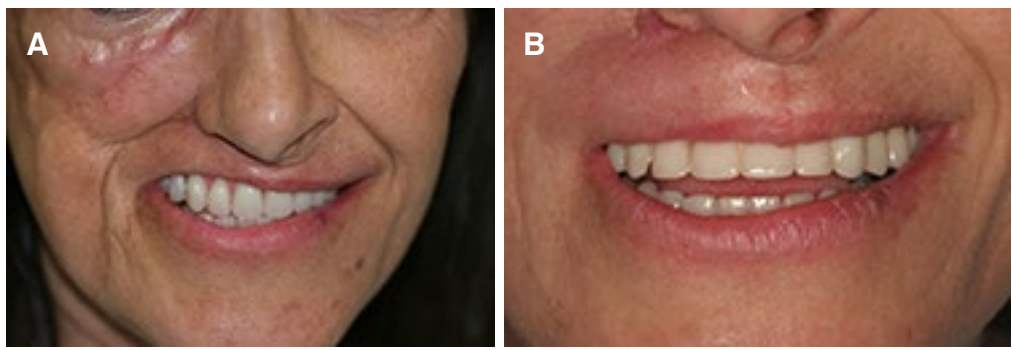

Figure 4. (A) The classic appearance of the shortened and retracted upper lip after primary reconstruction and adjuvant radiation therapy; (B) inset of the radial forearm free flap lengthens the lip and vestibule and improves the lip-to-tooth relationship

Numerous techniques of vestibuloplasty are available to lengthen the vestibule such as submucosal vestibuloplasty, open vestibuloplasty with secondary re-epithelialization, transpositional vestibuloplasty and skin grafting ${ }^{[1]}$. In the irradiated patient, these techniques have a limited role due to the poor vascular supply, scaring and fibrosis and limited tissue laxity. The unpredictable outcome of these procedures also carries a significant risk for hardware exposure, poor healing and wound dehiscence. Pedicled flaps using the facial artery myomucosal flap and the nasolabial flap have been used in the past ${ }^{[2,3]}$. However, in the post-ablative irradiated patient, these flaps have limited role due to the limited amount of tissue available for transfer, the need for intact facial artery which is often compromised after ablative surgery, and the presence within the zone of external beam radiation ${ }^{[4]}$.

The deformity of the recalcitrant upper lip results from skin, muscle and mucosal tissue loss and fibrosis. Therefore, full-thickness reconstruction is essential to restore the length and thickness of the upper lip and re-establish the maxillary vestibule. Vascularized free tissue provides the best method of reconstruction in these patients.

St-Hilaire et al. ${ }^{[4]}$ described 13 patients with intractable vestibules secondary to tumor extirpation, traumatic injuries and infections. They used the ulnar and anterolateral thigh flap to reconstruct the oral vestibule. In our case series, the patients had lip and vestibular deformity secondary to tumor extirpation and/or radiotherapy. In two patients, the deficiency of soft tissue was full thickness, and required tissue augmentation to the mucosal and cutaneous surfaces to allow lengthening of the lip and vestibule. We chose the RFFF which was ideal to provide thin and pliable tissue with a long vascular pedicle. It also allowed complex design of the skin to resurface the mucosal and cutaneous linings.

The flap is harvested in the standard technique. The skin is de-epithelialized in the middle segment [Figure 6]. The recipient site is prepared by making an incision at the depth of the vestibule to release the upper lip. Another incision is made at the base of the nose to allow lip lengthening. The two incisions are connected and the area is widely undermined to allow the flap inset. The de-epithelized segment is tunneled and the epithelized segments are inset at the base of the nose to lengthen the lip, and the depth of the vestibule to lengthen the neo-vestibule [Figure 1B].

Subjective outcome assessment was performed in all patients. All patients were satisfied with final aesthetic improvement. All patients were able to wear dental prosthesis and had improved lip competence, speech, mastication and bolus control.

We recognize the limitations of this study which include the retrospective case series design and the subjective outcome assessment. The purpose of this study was to demonstrate a surgical technique which is useful in a challenging clinical problem. This case series highlights the importance of secondary refinements after primary reconstruction and radiation therapy to improve the aesthetic and functional 


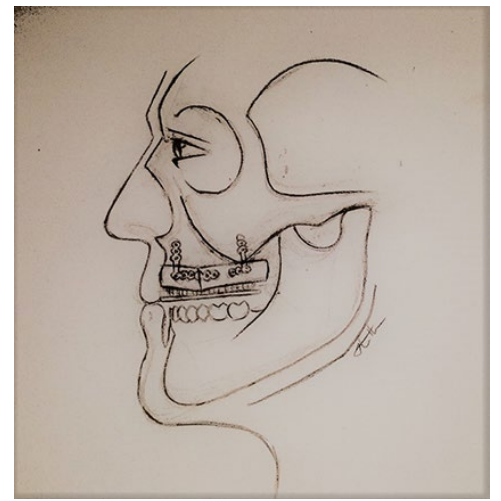

Figure 5. Loss of the vestibule after primary reconstruction when the skin paddle is sutured to the labial mucosa

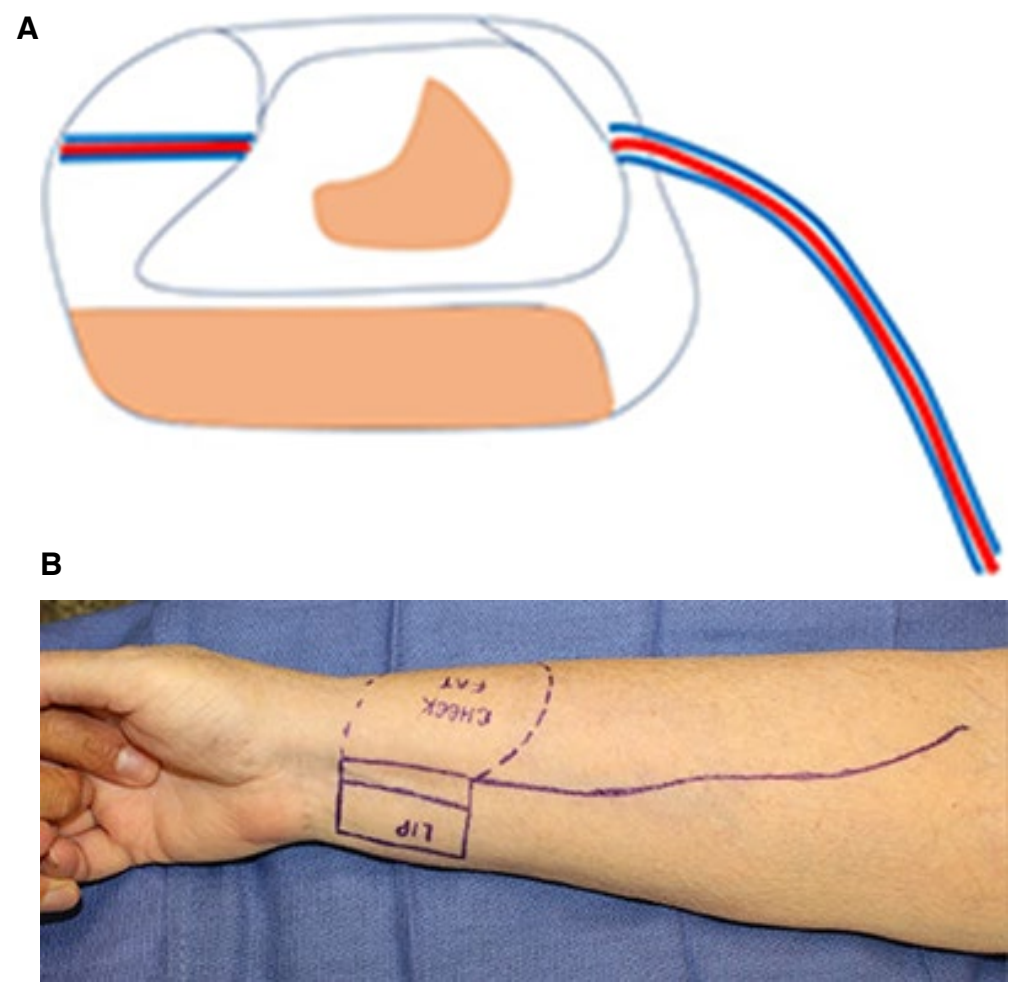

Figure 6. The skin is de-epithelialized in the middle segment leaving cutaneous and mucosal epithelized surfaces (A and B)

outcome. The RFFF provides an ideal method of reconstruction for the recalcitrant upper lip.

\section{DECLARATIONS}

\section{Authors' contributions}

Conception and design, data acquisition, drafting the article, revising and final approval: Al Shetawi AH Conception and design, drafting the article, revising and final approval: Fernandes $\mathrm{R}$

\section{Financial support and sponsorship}

None.

\section{Conflicts of interest}

There are no conflicts of interest. 


\section{Patient consent}

All patients were consented per the University protocol.

\section{Ethics approval}

Not required for case reports per the University protocol.

\section{Copyright}

(c) The Author(s) 2018.

\section{REFERENCES}

1. Miloro M, Ghali GE, Larsen P, Waite P. Peterson's Principles of Oral and Maxillofacial Surgery, 3rd edition. PMPH-USA; 2011. p. 142-7.

2. Hatoko M, Kuwahara M, Tanaka A, Yurugi S. Use of facial artery musculomucosal flap for closure of soft tissue defects of the mandibular vestibule. Int J Oral Maxillofac Surg 2002;31:210-1.

3. Fernandes R. Chapter 7: Nasolabial flap. Local and Regional Flaps in Head and Neck Reconstruction: A Practical Approach. WileyBlackwel; 2014. p. 47-9.

4. St-Hilaire H, Mithani SK, Rodriguez ED. Microsurgical salvage of the intractable oral vestibule. Plast Reconstr Surg 2009;123:331-8. 